\title{
THE GUARDIAN DECLINED TO PUBLISH THE FOLLOWING LETTER ON PEAK GLOBAL OIL SUPPLY IN 2020
}

\section{Sir/Madam}

The article by Terry McAlister and George Monbiot (15 December , p.9), reporting that the International Energy Agency now claims that the world's oil supply peak will occur in 2020 , is grossly misleading.

The organisation's newly published 2008 World Energy Outlook (which with its 500 pages is double the size of all previous years' reports!) presents a comprehensive and formidable view of all future prospects for energy, but it is most productive in its greatly extended analysis compared with earlier years on the prospects for the continuing expansion of oil supplies.

First, it calculates and explains the size of the world's oil wealth, viz. at about 6.5 trillion barrels - of which only 1.1 trillion have been used. The remaining 5.4 trillion barrels are defined as having production costs which range from $\$ 10$ to 40 per barrel for conventional oil, to $\$ 40$ - 120 per barrel for the exploitation of oil shales. The latter are defined as unlikely to be produced in large volumes before 2030 .

Meanwhile, the Report's other sets of calculations indicate a continuing rising supply of conventional oil from its 80.7 million barrels per day in 2007 to 94.8 million b/d in 2030 (the end-year of the IEA's investigations). Over the next 23 years this implies a modest average $1.1 \%$ per annum increase in oil supplies, but the Report then also shows a rapidly rising $5.5 \%$ growth in the production of non-conventional oil over the same period so that demand can be met.

This latter phenomenon will also (post-2030) enable oil supplies to continue to grow, albeit then constrained in competition for energy markets by natural gas and renewables.

Peter R Odell

Professor Emeritus of International Energy Studies, Erasmus University, Rotterdam 
